\title{
Comparison in the Management of Respiratory Failure due to Bronchiolitis in a Pediatric ICU Between 2010 and 2016
}

\author{
Flavia Toni, Francisco José Cambra Lasaosa, Giorgio Conti, Laura Escuredo, Sergio Benito, \\ Gemma Gelabert, and Martí Pons-Òdena
}

\begin{abstract}
BACKGROUND: In recent years, respiratory support in severe bronchiolitis has changed in several aspects: increased use of noninvasive ventilation, new equipment, and implementation of high-flow nasal cannula therapy. OBJECTIVE: To analyze the effectiveness of the changes progressively introduced in the respiratory support of patients with bronchiolitis to reduce the intubation rate. METHODS: This was a retrospective, observational, descriptive study. Patients admitted to the pediatric ICU of Hospital Sant Joan de Déu (Barcelona, Spain) with respiratory failure due to bronchiolitis in the 2010-2011 and 2016-2017 periods were included. Exclusion criteria were the following: patients who were previously intubated and tracheostomized and patients $>1 \mathrm{y}$. Data collected were demographic, clinical, and ventilatory variables, including the type, equipment used, and length of the respiratory support received. RESULTS: A total of 161 subjects were included: 53 in the 2010-2011 period and 108 in the 2016-2017 period. No clinical differences were observed except the incidence of previous apnea, a diagnosis of sepsis, and procalcitonin values on admission that were higher in the first period. High-flow nasal cannula use before pediatric ICU admission was significantly higher in 2016-2017. A significant increase in the use of the total face mask was observed. The need for invasive ventilation decreased from $37.7 \%$ to $17.5 \%$. In the multivariate study, use of interfaces other than the total face mask was identified as the only independent predictive factor for noninvasive ventilation failure, with an odds ratio of 2.5 , 95\% CI 1.04-6.2 $(P=.040)$. CONCLUSIONS: An important reduction in invasive ventilation was observed. An independent predictive factor for noninvasive ventilation failure was in using an interface other than the total face mask. Implementation of high-flow nasal cannula has not been identified as an independent protective factor for intubation. Key words: acute respiratory failure; bronchiolitis; high-flow nasal cannula; pediatric; pediatric ICU; total face mask. [Respir Care 2019;64(10):1270-1278. () 2019 Daedalus Enterprises]
\end{abstract}

\section{Introduction}

In recent years, respiratory support for patients admitted to the pediatric ICU due to severe bronchiolitis has evolved

\footnotetext{
Drs Toni and Conti are affiliated with the Department of Anesthesiology and Intensive Care, Università Cattolica del Sacro Cuore, Fondzione Policlinico Agostino Gemelli, Rome, Italy. Drs Cambra, Escuredo, Benito, and Pons-Odena are affiliated with the Pediatric Intensive and Intermediate Care Department, Sant Joan de Déu University Hospital, Universitat de Barcelona, Esplugues de Llobregat, Spain. Drs Cambra and PonsÒdena also are affiliated to Critical Care Research Group, Institut de Recerca Sant Joan de Déu, Santa Rosa 39-57, 08950 Esplugues de Llobregat, Spain. Dr Gelabert is affiliated with Medical Records and Clinical Coding Service, Sant Joan de Déu University Hospital, Universitat de Barcelona, Esplugues de Llobregat, Spain.
}

in several aspects: increased use of noninvasive ventilation $(\mathrm{NIV})^{1}$; newer interfaces ${ }^{2}$ and ventilators to administer NIV; and the implementation of high-flow nasal cannula (HFNC) in the pediatric $\mathrm{ICU}^{3}$ as well as its early use in

\footnotetext{
Dr Pons-Òdena discloses relationships with ResMed, Fisher and Paykel, and Air Liquide Healthcare. The remaining authors have disclosed no conflicts of interest.

Correspondence: Francisco José Cambra Lasaosa PhD, Pediatric Intensive and Intermediate Care Department, Sant Joan de Déu University Hospital, Universitat de Barcelona, Passeig Sant Joan de Déu 2, 08950 Esplugues de Llobregat, Spain. E-mail: fjcambra@sjdhospitalbarcelona.org.
}

DOI: $10.4187 /$ respcare.06608 
general wards ${ }^{4}$ or emergency departments. ${ }^{5}$ There is no consensus on the optimal management of respiratory failure in this group of patients. A wide variability exists in the use of different respiratory support techniques among countries ${ }^{6,7}$ and even within the same country. ${ }^{8,9}$ There is a lack of knowledge about the real value of each tool available for the management of respiratory failure in bronchiolitis. Recently, randomized controlled trials showed that early and generalized use of HFNC in mild-moderate bronchiolitis slightly reduced the percentage of pediatric ICU admissions. ${ }^{10,11}$ Interestingly, in both studies, the control group used HFNC as a rescue treatment and achieved similar results in preventing pediatric ICU admission.

Data about the effectiveness of different NIV devices and interfaces in young infants are scarce. The theoretical superiority of bi-level positive airway pressure (BPAP) over CPAP is also unclear. ${ }^{12} \mathrm{~A}$ randomized controlled trial by Yañez et al $^{13}$ used critical care ventilators with an NIV option more suitable for subjects who weighed $<10 \mathrm{~kg}$ than older ventilators designed to deliver only NIV. However, there is no information that compared devices used to deliver NIV to newer NIV ventilators.

The main objective of this study was to describe and analyze the potential effectiveness of each change in respiratory support implemented in a pediatric ICU over a 6-y period for subjects with acute respiratory failure due to bronchiolitis by comparing 2 periods: autumn-winter 2010 2011 and autumn-winter 2016-2017. Some studies suggested HFNC reduced the intubation rate $^{3}$ and, consequently, the length of stay (LOS). The second objective was to evaluate the impact of HFNC on LOS in the hospital and the pediatric ICU.

\section{Methods}

An observational, retrospective, descriptive, and comparative study was performed in subjects ages $<1$ year who were admitted, in the autumn-winter periods of 20102011 and 2016-2017, to the pediatric ICU of Hospital Sant Joan de Déu in Barcelona with a diagnosis of bronchiolitis. The institutional review board of Hospital Sant Joan de Déu waived the need for written consent due to the use of anonymous data and the complexity of obtaining written consent from the parents of infants included in the first period.

Study inclusion criteria were identical to criteria used for admission to the pediatric ICU: clinical deterioration of the subject due to severe acute respiratory failure (defined as a progressive increase in the work of breathing despite medical treatment or the presence of frequent apnea with bradycardia or cyanosis), $\mathrm{F}_{\mathrm{IO}_{2}}$ needs to be $>0.4$ to maintain $\mathrm{S}_{\mathrm{pO}_{2}}>92 \%$ or $\mathrm{P}_{\mathrm{CO}_{2}}>55 \mathrm{~mm} \mathrm{Hg}$ from capillary or venous blood gases. HFNC was delivered with an airoxygen blender to accurately measure $\mathrm{F}_{\mathrm{IO}_{2}}$ before NIV

\section{QUICK LOOK}

\section{Current knowledge}

Interface selection is a key point for noninvasive ventilation success. Intolerance of the interface can lead to discomfort, non-adherance, and failure of the therapy.

\section{What this paper contributes to our knowledge}

The use of a total face mask was identified among several changes that occurred between 2010 and 2016 as the only independent predictive factor for noninvasive ventilation success in infants diagnosed with bronchiolitis.

initiation. The $\mathrm{F}_{\mathrm{IO}_{2}}$ of low-flow oxygen was assumed to increase by $4 \%$ for every additional $\mathrm{L} / \mathrm{min}$ administered. HFNC was only continued if the Bronchiolitis Score of Sant Joan de Déu dropped below 8 after admission. CPAP was selected to treat subjects with mild apnea, BPAP was used for the remaining subjects. Criteria for immediate intubation and mechanical ventilation included contraindications for NIV, such as severe apnea, an inability to protect the airway, moderate-to-severe ARDS, hemodynamic instability, and signs of imminent respiratory arrest.

In the first period (2010-2011), some subjects received treatment with HFNC (in the emergency department or on the general wards) with flows of $1 \mathrm{~L} / \mathrm{kg} / \mathrm{min}$ and a maximum $\mathrm{F}_{\mathrm{IO}_{2}}$ of 0.4. In the second period (2016-2017), the majority of the subjects received HFNC with flows of $2 \mathrm{~L} / \mathrm{kg} / \mathrm{min}$ and a maximum $\mathrm{F}_{\mathrm{IO}_{2}}$ of 0.4 . In the subjects who were treated with HFNC, the following criteria were added to the general pediatric ICU admission criteria: heart rate $>150$ beats/min and/or breathing frequency $>50$ breaths $/ \mathrm{min}$ and/or the Bronchiolitis Score of Sant Joan de Déu $>8$ at $2 \mathrm{~h}$ of treatment. ${ }^{14}$ Ventilator and mode selection followed the protocol of the pediatric ICU based on the study by Yañez et al. ${ }^{13}$ Critical care ventilators in assisted-controlled pressure mode were used for infants $<3$ months old and NIV-specific ventilators were used in the spontaneous/timed mode for older infants.

The exclusion criteria were patients who were intubated or tracheostomized before pediatric ICU admission and those who developed nosocomial bronchiolitis so to keep the studied population homogeneous. In accordance with by the criteria of McConnochie, ${ }^{15}$ infants with previous episodes of wheezing and bronchiolitis and of wheezing related to other conditions were also excluded as well as patients ages $>12$ months. The criteria used for intubation and mechanical ventilation were the following: inability to reduce the work of breathing, measured as the subject maintaining or increasing his or her heart rate and/or breathing frequency; persistent hypoxemia, defined by $\mathrm{F}_{\mathrm{IO}_{2}}>0.8$, 


\section{Management of Respiratory FailuRe IN THE PICU}

hypercapnia $\mathrm{P}_{\mathrm{CO}_{2}}>75 \mathrm{~mm} \mathrm{Hg}$, acidosis $\mathrm{pH}<7.20$, and whenever the subject developed a contraindication for NIV as previously mentioned.

Data collection was carried out by using an electronic chart review of the patients admitted to the pediatric ICU for bronchiolitis in the aforementioned periods: 2010-2011 and 2016-2017. For every subject who met the inclusion criteria, the following variables were collected: age, sex, weight, underlying risk factors for severe bronchiolitis (eg, prematurity, cardiac disease, bronchopulmonary dysplasia), Bronchiolitis Score of Sant Joan de Déu for the work of breathing in bronchiolitis, presence of respiratory syncytial virus in nasal secretions, suspicion of secondary bacterial infection (sepsis, respiratory co-infection, community-acquired pneumonia or ventilator-associated pneumonia for subjects who were intubated, urinary tract infection), type of respiratory support (HFNC, NIV that uses CPAP and/or BPAP, and invasive mechanical ventilation, along with their respective duration of use), type of ventilator, type of NIV interface, vital signs on admission (heart rate, breathing frequency, $\mathrm{S}_{\mathrm{pO}_{2}} / \mathrm{F}_{\mathrm{IO}_{2}}$ ), PRISM (Pediatric Risk of Mortality) III score, and settings at $2 \mathrm{~h}$ (inspiratory positive airway pressure, expiratory positive airway pressure, and $\mathrm{F}_{\mathrm{IO}_{2}}$ ).

For subjects who were intubated, the number of hours on invasive ventilation was documented as well as the total hours on NIV support before and after intubation, with CPAP and BPAP documented separately. Numerical data of subjects treated with invasive ventilation before pediatric ICU admission were collected but were not included in the statistical analysis of the present study. The location of the subject before pediatric ICU admission (general ward, emergency department, other hospitals) was documented as well as the pediatric ICU and hospital LOS. Secondary bacterial infection was diagnosed when blood test markers on admission showed an increase of C-reactive protein $>60 \mathrm{mg} / \mathrm{dL}$ or procalcitonin $>2 \mathrm{ng} / \mathrm{mL},{ }^{16}$ or positive cultures (blood, bronchoalveolar lavage, and/or urine). Sepsis was defined by following the criteria used in the pediatric ICU, published before 2010. ${ }^{17}$ Respiratory syncytial virus was detected in nasal secretions when using immunochromatographic membrane strip assays. The primary outcome was the intubation rate. Secondary outcomes were pediatric ICU and hospital LOS.

Categorical variables were expressed as percentages, and continuous variables were expressed as mean \pm SD if normally distributed, or median and interquartile range otherwise. Quantitative continuous variables were compared among the groups by using the unpaired Student $t$ test or the Mann-Whitney test accordingly. Kaplan-Meier survival curves for the time on BPAP until discontinuation or intubation were applied for each ventilator-interface combination in each period. The log-rank test was used for statistical significance. The impact of each change intro- duced in this period was evaluated by a multivariate analysis (binary logistic regression by using the stepwise approach). Results for the stepwise binary logistic regression were expressed as odds ratio and their 95\% CI. Stata 12.0 software (StataCorp, College Station, Texas) was used.

\section{Results}

A total of 161 subjects were studied: 53 in the first period (2010-2011) and 108 in the second period (20162017). These samples represented $22 \%(2010-2011)$ and $20 \%$ (2016-2017), respectively, of patients ages $<1$ year diagnosed with bronchiolitis and admitted to the hospital in each period (241 and 540, respectively). There were 26 subjects between 6 and 12 months of age. No differences were found in age, sex, weight, and the Bronchiolitis Score of Sant Joan de Déu between the 2 periods, although the Bronchiolitis Score of Sant Joan de Déu was unavailable for $\sim 70 \%$ of the subjects. There were no betweengroup differences in the various underlying risk factors for the development of severe bronchiolitis, which could have led to epidemiologic differences between the study periods. The characteristics of the subjects and respiratory support received are shown in Table 1. The incidence of apnea before admission was higher in the first period, $20.7 \%$ of the subjects compared with $6.5 \%$ in the second period $(P=.02)$. The number of subjects admitted for bronchiolitis caused by respiratory syncytial virus increased significantly in the second period $(P=.003)$.

No differences existed in the number of subjects with a secondary bacterial infections (for the 3 types analyzed: urinary tract infection, respiratory co-infection, pneumonia) between the 2 periods. However, an important difference was observed in the incidence of diagnosed sepsis between the periods $(9.4 \%(2010-2011)$ versus $0.9 \%$ (2016-2017)) $(P=.02)$, with an intubation rate of $66 \%$ in this group. With regard to the subject's location before pediatric ICU admission (emergency department, general ward, other hospitals), no differences were seen between the 2 periods. In both periods, some subjects arrived at the pediatric ICU already intubated, 5 in the first period and 2 in the second period, with a statistically significant difference $(P=.049)$. The subjects did not have any differences in heart rate or breathing frequency on pediatric ICU admission between the 2 periods. However, statistically significant differences were found in the $\mathrm{S}_{\mathrm{pO}_{2}} / \mathrm{F}_{\mathrm{IO}_{2}}$ values (233 in 2010-2011 versus 252 in 2016-2017, $(P=.004)$ and PRISM III scores $(P=.003)$.

Respiratory support during the first period was provided exclusively with HFNC in 1 subject and with exclusive invasive ventilation in 4 subjects, whereas NIV was initially used in 48 subjects. In the second period, HFNC was used exclusively in 4 subjects and exclusive invasive ventilation in 5 subjects, and NIV was initially used in 99 sub- 
Table 1. Demographic and Clinical Variables Before Admission

\begin{tabular}{|c|c|c|c|}
\hline Variable & 2010-2011 & 2016-2017 & $P$ \\
\hline Subjects, $n$ & 53 & 108 & \\
\hline Boys & $33(62)$ & $61(56.5)$ & .60 \\
\hline Weight, mean \pm SD kg & $5.07 \pm 2.1$ & $4.8 \pm 2$ & .53 \\
\hline Age, d median (range) & $51(23-171)$ & $46.5(26.5-98.5)$ & .18 \\
\hline Underlying condition, $n(\%)$ & $14(26.4)$ & $31(28.7)$ & .90 \\
\hline Prematurity & $9(17)$ & $20(18)$ & .98 \\
\hline Cardiac & $7(13.2)$ & $5(4.6)$ & .10 \\
\hline Bronchopulmonary dysplasia & $1(1.9)$ & $0(0)$ & .71 \\
\hline Other & $7(13.2)$ & $10(9.2)$ & .44 \\
\hline Apnea, $n(\%)$ & $11(20.7)$ & $7(6.5)$ & .02 \\
\hline $\mathrm{RSV}, n(\%)$ & $37(69.8)$ & $96(89)$ & .003 \\
\hline Bacterial infection, $n(\%)$ & $14(26)$ & $23(21.3)$ & .60 \\
\hline Urinary & $0(0)$ & $5(4.6)$ & .17 \\
\hline Respiratory & $9(17)$ & $17(16)$ & .98 \\
\hline Sepsis & $5(9.4)$ & $1(0.9)$ & .02 \\
\hline CAP, $n(\%)$ & $4(7.5)$ & $3(2.7)$ & .33 \\
\hline C-reactive protein, $\mathrm{mg} / \mathrm{dL}$ PCT $\mathrm{mmol} / \mathrm{L}$ & $(n=50) 34.8 \pm 36.2$ & $(n=96) 31.5 \pm 34$ & .59 \\
\hline PCT, median (range) $\mathrm{ng} / \mathrm{mL}$ & $(n=40) 0.5(0.2-4.35)$ & $(n=81) 0.3(0.14-1.04)$ & .045 \\
\hline Admission heart rate, beats/min & $166 \pm 26$ & $162 \pm 22$ & .27 \\
\hline Admission frequency, breaths/min & $42 \pm 13.5$ & $45 \pm 13$ & .19 \\
\hline $\mathrm{S}_{\mathrm{pO}_{2}} / \mathrm{F}_{\mathrm{IO}_{2}}$, median (range) & $233(200-285)$ & $252(222-321.5)$ & .004 \\
\hline BROSJOD, mean $\pm \mathrm{SD}$ & $(n=13) 10.3 \pm 3.3$ & $(n=28) 10.3 \pm 2$ & .89 \\
\hline PRISM III, mean $\pm \mathrm{SD}$ & $2.88 \pm 3.67$ & $1.47 \pm 2.24$ & .003 \\
\hline \multicolumn{4}{|l|}{ Admitted from, $n(\%)$} \\
\hline General ward & $26(49)$ & $48(44.5)$ & .58 \\
\hline Emergency department & $12(23)$ & $21(19.4)$ & .63 \\
\hline From another hospital (transported) & $15(28)$ & $39(36.1)$ & .45 \\
\hline $\begin{array}{l}\text { RSV }=\text { respiratory syncytial virus } \\
\text { CAP }=\text { community-acquired pneumonia } \\
\text { PCT }=\text { procalcitonin } \\
\text { BROSJOD = bronchiolitis score of saint john of god } \\
\text { PRISM = pediatric risk of mortality }\end{array}$ & & & \\
\hline
\end{tabular}

jects. The use of initial HFNC before pediatric ICU admission was significantly greater in the second period $(P<.001)$. A $5 \%$ decrease in admissions from the general wards was observed. The use of initial BPAP increased $(P=.009)$. The number of subjects who required invasive ventilation decreased from $37.7 \%$ to $17.5 \%$ in the second period $(P=.005)$, as shown in Table 2 . Inspiratory positive airway pressure values at $2 \mathrm{~h}$ were significantly lower during the second period (Table 2).

With respect to the respiratory support used in the weaning process, a significant rise in the use of CPAP after intubation $(P<.001)$ and HFNC after intubation $(P<.001)$ stood out in the second period, but no increase was observed in the use of BPAP after intubation. Use of HFNC during the weaning process was associated with use before pediatric ICU admission, $(P=.01$, chi-square test). Total NIV hours were significantly higher in the second period $(P=.02)$. In the first period, the median (interquartile range) duration of BPAP in the subjects in whom intubation was avoided was 74 (58.5-106.5) h, compared with
$106(72-139) \mathrm{h}$ in the second period $(P=.038)$. No differences existed in the total hours on invasive ventilation between the 2 periods. As for the interfaces used, a statistically significant increase in the use of the total face mask $(P<.001)$ and a decrease in the use of the nasopharyngeal tube $(P<.001)$ were observed in the second period. No significant differences were found in the type of ventilator used (Servo-i [Maquet, Wayne, New Jersey] and turbine ventilators like BiPAP Vision, V60 [Philips, Carlsbad, California], Carina [Dräger, Lübeck, Germany]). With regard to the ventilator-interface combinations used in the second period, there was a higher use of the total face mask with the Servo-i than with the V60 [Philips, Carlsbad, California], despite the latter being slightly more effective (Table 3 and Fig. 1).

No significant differences were found in mean \pm SD pediatric ICU LOS, 8.4 days \pm 8.3 in the first period compared with 6.7 days \pm 4.5 in the second period $(P=.09)$, although a reduction of 1.6 days was observed. In the 2016-2017 period, the total hospital and post-pe- 


\section{Management of Respiratory Failure IN THE PICU}

Table 2. Respiratory Support Received Before, During, and After Pediatric ICU Admission

\begin{tabular}{|c|c|c|c|}
\hline Parameter & 2010-2011 & 2016-2017 & $P$ \\
\hline \multicolumn{4}{|l|}{ Before pediatric ICU admission, $n(\%)$} \\
\hline Invasive ventilation & $5(8.6)$ & $2(1.8)$ & .039 \\
\hline HFNC & $23(43.3)$ & $93(86.1)$ & $<.001$ \\
\hline \multicolumn{4}{|l|}{ During pediatric ICU admission, $n(\%)$} \\
\hline Only HFNC & $1(1.8)$ & $4(3.7)$ & .51 \\
\hline Only CPAP & $7(13)$ & $0(0)$ & $<.001$ \\
\hline Only BPAP & $21(39)$ & $72(66.6)$ & $<.001$ \\
\hline $\mathrm{CPAP}+\mathrm{BPAP}$ & $4(7.5)$ & $13(12)$ & .035 \\
\hline $\mathrm{CPAP}+$ invasive ventilation & $1(1.8)$ & $1(0.9)$ & .58 \\
\hline BPAP + invasive ventilation & $14(26.4)$ & $12(11)$ & .01 \\
\hline $\mathrm{CPAP}+\mathrm{BPAP}+$ invasive ventilation & $1(1.9)$ & $1(0.9)$ & .58 \\
\hline Only invasive ventilation (started in the pediatric ICU) & $4(7.5)$ & $5(4.6)$ & .45 \\
\hline Total BPAP & $40(75.4)$ & $98(90.7)$ & .01 \\
\hline Total invasive ventilation (started in the pediatric ICU) & $20(37.7)$ & $19(17.5)$ & .005 \\
\hline BPAP after invasive ventilation & $10(18.8)$ & $19(17.5)$ & .84 \\
\hline CPAP after invasive ventilation or after BPAP & $28(52.8)$ & $90(83.3)$ & $<.001$ \\
\hline HFNC after invasive ventilation/NIV & $11(20.7)$ & $74(68.5)$ & $<.001$ \\
\hline \multicolumn{4}{|l|}{ Settings at $2 \mathrm{~h}$} \\
\hline IPAP, median $\mathrm{cm} \mathrm{H}_{2} \mathrm{O}$ (range) & $14(13-16)$ & $13(11-14)$ & .03 \\
\hline EPAP, median $\mathrm{cm} \mathrm{H}_{2} \mathrm{O}$ (range) & $6(6-7)$ & $6(6-7)$ & .76 \\
\hline $\mathrm{F}_{\mathrm{IO}_{2}}$, median (range) & $0.40(0.35-0.45)$ & $0.35(0.30-0.45)$ & .06 \\
\hline \multicolumn{4}{|l|}{ Duration of respiratory support, mean $\pm \mathrm{SD} \mathrm{h}$} \\
\hline NIV (CPAP + BPAP) & $80 \pm 7$ & $107 \pm 6$ & .02 \\
\hline CPAP & $38 \pm 33$ & $9 \pm 9$ & .004 \\
\hline BPAP, median (range) & $51.5(9.5-87.5)$ & $83(48-121)$ & .001 \\
\hline Invasive ventilation & $198 \pm 140$ & $242 \pm 96$ & .25 \\
\hline CPAP after invasive ventilation, median (range) & $13(7-25.5)$ & $7(3-22)$ & .006 \\
\hline $\begin{array}{l}\text { HFNC }=\text { high-flow nasal cannula } \\
\text { BPAP = bi-level positive airway pressure } \\
\text { NIV = noninvasive ventilation } \\
\text { IPAP = inspiratory positive airway pressure } \\
\text { EPAP = expiratory positive airway pressure }\end{array}$ & & & \\
\hline
\end{tabular}

diatric ICU LOS for the subjects who received HFNC before NIV were significantly reduced compared with the 2010-2011 period, $P=.02$ and $P=.03$ respectively (Table 4). Hospital LOS after pediatric ICU was also significantly shorter in the subjects who received pre-NIV HFNC compared with those who did not $(P=.040)$ in the 2016-2017 period.

\section{Multivariate Study}

The following variables were introduced in the multivariate model (binary logistic regression): age, apnea before admission, a diagnosis of sepsis, HFNC use, and total face mask use compared with other interfaces. An independent predictive factor for intubation was the use of interfaces other than the total face mask, with an odds ratio of $2.53,95 \%$ CI 1.044-6.17 ( $P=.040)$. A multivariate analysis was also performed and excluded subjects with a diagnosis of sepsis because NIV failure in many of these cases was due to the appearance of a clinical contraindication to NIV (hemodynamic instability) rather than a failure of the technique itself. Age, apnea before admission, HFNC use, and total face mask use compared with the rest of the interfaces were introduced into the model. The only independent predictive factor for intubation was also the use of interfaces other than the total face mask, with an odds ratio of $2.43,95 \%$ CI $1.22-6.68(P=.02)$.

\section{Discussion}

The most significant finding of this study was the reduction in the need for invasive ventilation in this population from $37.7 \%$ in the first period to $17.5 \%$ in the second period $(P=.005)$. Evidently, many factors could be involved in this decrease of invasive ventilation. According to the literature, a decreased need for invasive ventilation is associated with factors such as the introduction of HFNC, ${ }^{3,5}$ the use of CPAP, ${ }^{18}$ or NIV. ${ }^{19}$ This study tried to 


\section{Management of Respiratory Failure IN THE PICU}

Table 3. Equipment Used for NIV

\begin{tabular}{|c|c|c|c|c|}
\hline Variables & 2010-2011, n(\%) & 2016-2017, n(\%) & $P$ & NIV Effectiveness (\%) \\
\hline \multicolumn{5}{|l|}{ Interfaces } \\
\hline Subjects & 46 & 99 & & \\
\hline Nasopharyngeal tube & $29(66)$ & $4(3.9)$ & $<.001$ & 62 \\
\hline Total face mask & $0(0)$ & $92(93.2)$ & $<.001$ & 84 \\
\hline Adult nasal as oronasal mask for infant & $9(18)$ & $1(0.97)$ & .14 & 30 \\
\hline Nasal & $5(10)$ & $1(0.97)$ & .95 & 83 \\
\hline Oronasal & $3(6)$ & $1(0.97)$ & .44 & 75 \\
\hline \multicolumn{5}{|l|}{ Ventilators } \\
\hline Subjects & 48 & 99 & & \\
\hline Invasive (Servo-i) & $24(50)$ & $75(75)$ & .003 & 75 \\
\hline Turbine (V60, Carina, BiPAP Vision) & $13(27)$ & $23(23)$ & .71 & $\begin{array}{l}\text { V60, 95; Carina, 25; } \\
\text { Vision } 70\end{array}$ \\
\hline Others & $11(23)$ & $1(1)$ & $<.001$ & \\
\hline \multicolumn{5}{|l|}{ Interface + ventilator } \\
\hline Subjects & 46 & 99 & & \\
\hline Nasopharyngeal tube + Servo-i & $22(50)$ & $4(3.9)$ & $<.001$ & 63 \\
\hline Total face mask + Servo-i & $0(0)$ & $73(71)$ & $<.001$ & 81 \\
\hline Other interfaces + Servo-i & $0(0)$ & $2(1.9)$ & .33 & 33 \\
\hline Total face mask + BiPAP Vision & $0(0)$ & $1(0.9)$ & .030 & 100 \\
\hline Total face mask $+\mathrm{V} 60$ & $0(0)$ & $22(21.4)$ & $<.001$ & 95 \\
\hline Other interfaces + turbine (Carina, BiPAP Vision) & $12(25)$ & $0(0)$ & $<.001$ & 66 \\
\hline Other interfaces and other devices* & $12(25)$ & $1(0.9)$ & .01 & 84 \\
\hline
\end{tabular}

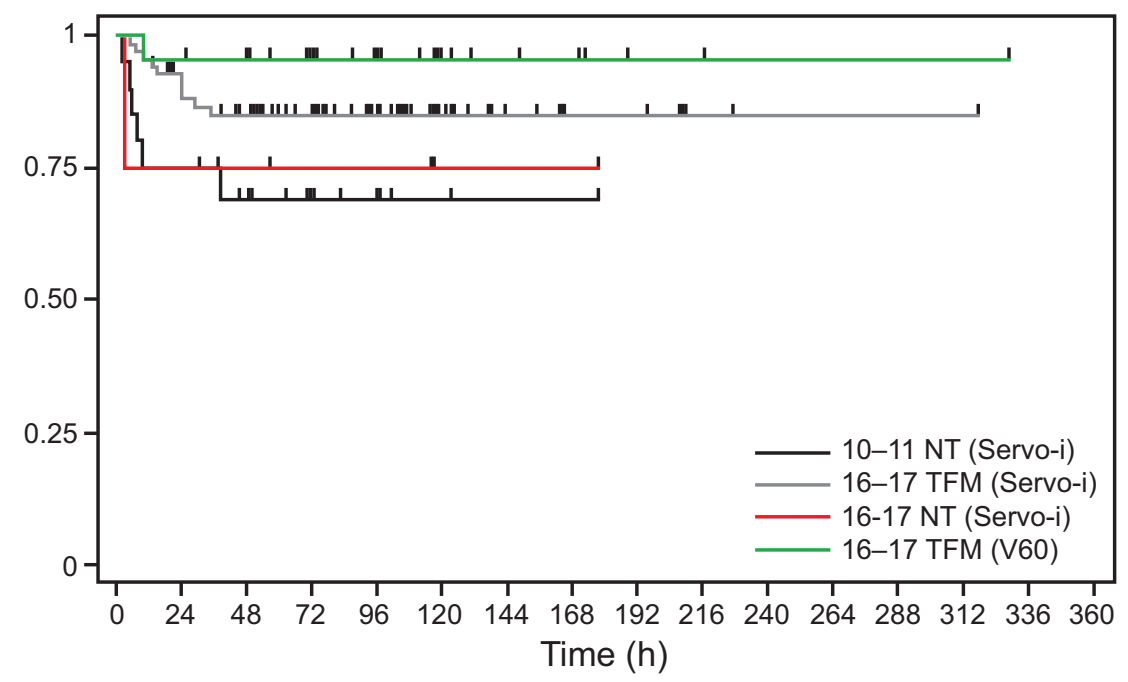

Fig. 1. Kaplan-Meier curves for the time on bi-level positive airway pressure (BPAP) until failure or censoring occurs according to the interface-ventilator. NT = nasopharyngeal tube; TFM = total face mask.

isolate the main factors potentially responsible for this finding through a multivariate analysis to minimize the inherent limitations of a retrospective study (biases, interacting and confounding factors). In this study, the risk of including subjects who had other pathologies despite meeting the criteria by McConnochie ${ }^{15}$ was minimized by ex- cluding patients ages $>1$ year. In addition, there were few subjects ages $>6$ months.

The analysis showed several differences between the 2 periods. First, although there were significant differences between time periods in $\mathrm{S}_{\mathrm{pO}_{2}} / \mathrm{F}_{\mathrm{IO}_{2}}$, we did not consider them clinically relevant because they corresponded 
Table 4. Hospital, Pediatric ICU, and Post-Pediatric ICU LOS According to the Use of HFNC in the Two Periods

\begin{tabular}{|c|c|c|c|c|c|c|c|c|c|}
\hline Parameter & 2010-2011 & 2016-2017 & $P$ & 2010-2011 & 2016-2017 & $P$ & 2010-2011 & 2016-2017 & $P$ \\
\hline & $\begin{array}{l}\text { Hospital } \\
\text { LOS (days) }\end{array}$ & $\begin{array}{l}\text { Hospital } \\
\quad \text { LOS (days) }\end{array}$ & & $\begin{array}{r}\text { Pediatric ICU } \\
\text { LOS (days) }\end{array}$ & $\begin{array}{l}\text { Pediatric ICU } \\
\text { LOS (days) }\end{array}$ & & $\begin{array}{l}\text { Post-Pediatric } \\
\text { ICU LOS (days) }\end{array}$ & $\begin{array}{l}\text { Post-Pediatric } \\
\text { ICU LOS (days) }\end{array}$ & \\
\hline $\mathrm{HFNC}$, mean $\pm \mathrm{SD}$ & $17.7 \pm 14.6$ & $13 \pm 6.8$ & .02 & $8.2 \pm 7.1$ & $6.85 \pm 4.7$ & .26 & $9 \pm 12$ & $5.8 \pm 4$ & .03 \\
\hline $\begin{array}{l}\text { Pre-pediatric ICU: } \\
\quad \text { yes, } n\end{array}$ & 23 & 93 & & 23 & 93 & & 23 & 93 & \\
\hline $\mathrm{HFNC}$, mean $\pm \mathrm{SD}$ & $15 \pm 14.5$ & $17 \pm 21$ & .67 & $8.6 \pm 9.2$ & $5.7 \pm 4.4$ & .27 & $5.6 \pm 8$ & $10.7 \pm 2$ & .25 \\
\hline $\begin{array}{l}\text { Pre-pediatric ICU: } \\
\text { no, } n\end{array}$ & 30 & 15 & & 30 & 15 & & 30 & 15 & \\
\hline \multicolumn{10}{|c|}{$\begin{array}{l}\text { LOS }=\text { length of stay (days) } \\
\text { HFNC }=\text { high-flow nasal cannula }\end{array}$} \\
\hline
\end{tabular}

to a difference in $\mathrm{F}_{\mathrm{IO}_{2}}$ of $<5 \%$. The PRISM III score was determined after $24 \mathrm{~h}$ of admission, which, hence, excluded it from being used as a predictor of NIV failure in the first $24 \mathrm{~h} .{ }^{20}$ It only indicated a posteriori that the subjects with the most severe physiologic and blood test marker alterations usually end up intubated, so the difference here was probably related to the number of subjects with sepsis between the 2 periods. Furthermore, the difference in the percentage of respiratory syncytial virus infections between the 2 periods could not be considered clinically important, as suggested by a previous study that did not find a difference in severity associated with an etiologic virus or the presence of viral co-infections. ${ }^{21}$ As for the differences in acquired bacterial infections between the 2 periods, the medians of C-reactive protein values were very similar and the median procalcitonin values were $<0.5$, compatible in any case with a diagnosis of localized bacterial infection. So the only statistical, but more importantly, clinical, differences between the 2 samples were the number of subjects who had apnea before admission, a sign clinically associated with the disease, 22 and the incidence of diagnosed sepsis, which led to the inclusion of both variables in the multivariate model.

There were no clinical or statistically significant differences in either period for physiologic variables, such as heart rate, breathing frequency, or $\mathrm{S}_{\mathrm{pO}_{2}}$, at admission. In addition, the percentage of pediatric ICU admissions from the general ward slightly decreased despite the enormous increase in the number of hospital admissions. However, inspiratory positive airway pressure values at $2 \mathrm{~h}$ were higher in the first period. Clinicians may have judged the subjects in the second period to be better at $2 \mathrm{~h}$; these individuals may have had less-severe acute respiratory failure due to the new admission criteria for patients on HFNC. When considering all the evidence, overuse of noninvasive respiratory support did not seem to be related to the reduced intubation rate, although this cannot be completely ruled out.
The only factor identified as an independent predictive factor for intubation in the multivariate analysis was the use of interfaces other than the total face mask. The increased use of HFNC before pediatric ICU admission slightly reduced the percentage of pediatric ICU admissions from the general wards, but it was neither statistically significant nor was it identified as an independent protective factor for NIV failure. The decreased need for invasive ventilation before pediatric ICU admission could perhaps be related to the early and better use of HFNC in the general ward before pediatric ICU admission as well as the introduction of respiratory support with NIV in the transport team. ${ }^{23}$

The greater use of the total face mask with the Servo-i ventilator rather than the turbine ventilator (V60) could be explained by the protocol of the pediatric ICU based on the clinical algorithm that prioritizes the use of these critical care ventilators in patients ages $<3$ months. ${ }^{13}$ The total face mask greatly minimizes the possibility of leaks, especially when compared with the nasopharyngeal tube, an essential factor for the success of NIV. Results of a randomized controlled trial in adults also suggested the superiority of the total face mask over the oronasal mask when NIV rescue was used. ${ }^{24}$

The change of ventilators used could also have influenced the results (Fig. 1), but the absence of statistical differences in the unilateral analysis and the reduced sample size led to the exclusion of this variable in the multivariate analysis. A new NIV-specific turbine ventilator, the V60, was introduced in this period in substitution of the BiPAP Vision [Philips, Carlsbad, California], but $<20 \%$ of the subjects used turbine ventilators in both periods. An adult study that used laboratory models showed a superiority of NIV-specific ventilators over critical care ventilators in their capacity to compensate for leaks and provide better synchronization. ${ }^{25}$ However, with neonatal models, notable differences were shown among different critical care ventilators, particularly with respect to inspiratory asynchrony. ${ }^{26}$ 


\section{Management of Respiratory FailuRe IN THE PICU}

It is noteworthy that the total hours on NIV were significantly higher in 2016, whereas the total hours on invasive ventilation were similar between the 2 periods. This could possibly be because the subjects with similar severity who were previously intubated were now successfully maintained on NIV, although more days of this support were needed. In addition, a significant decrease in the number of hours on CPAP after extubation between the 2 periods was observed. This could be explained by the increased use of HFNC after extubation in substitution of CPAP, which allowed for an early and safe discharge from the pediatric ICU to the general ward. ${ }^{27}$

Although the pediatric ICU LOS was shorter in general regardless of whether HFNC was used, this difference between the 2 periods was not statistically significant. However, a significant reduction, of $4.7 \mathrm{~d}$, in the average hospital LOS (due to a shortening of the average post-pediatric ICU LOS by $3.2 \mathrm{~d}$ ) was observed in the group that received HFNC before pediatric ICU admission. It was difficult to identify which mechanisms contributed to this finding. Several hypotheses were evaluated, for example, the improvement in the implementation of HFNC in the second period (2016-2017); pediatric consultants were more likely to use HFNC in the weaning of invasive ventilation if it had been used before admission (in ICU) or more likely, because there was an inadequate weaning protocol for HFNC during the first period (2010-2011). Unfortunately, there were many confounding factors and there was a lack of statistical power to perform an appropriate multivariate analysis; therefore, neither coincidence nor causality could be ruled out.

This study had clear limitations due to its retrospective nature and being a single-centered study. The availability of electronic charts in both periods allowed for collection of good-quality data, although it should be acknowledged that variables that measured the work of breathing on admission, such as the Bronchiolitis Score of Sant Joan de Déu, were frequently missing. Ultimately, it cannot be discounted that subjects in the second period had a lower severity of acute respiratory failure. The introduction of new pediatric ICU admission criteria (including betterdefined criteria for HFNC failure) might have played a part, although no differences were observed in clinical variables on admission or the percentage of pediatric ICU admissions. Furthermore, many confounding factors that could influence the outcomes were present. This was precisely why all the main known factors for NIV failure, such as age, apnea, type of interface, and use of HFNC were included in the multivariate study. Although providing a lower level of evidence than a randomized controlled trial, the multivariate study could offer valuable information to clinicians about the potentially helpful tools to reduce intubation rates in their centers.

\section{Conclusions}

When taking into account the limitations of the study design and the multivariate analysis, analysis of our data indicated that, among all the changes introduced progressively in the past 6 years, the implementation of the total face mask interface was the only independent predictive factor for a reduced intubation rate in subjects ages $<1 \mathrm{y}$ diagnosed with bronchiolitis. Increasing the use of HFNC before admission did not significantly reduce pediatric ICU admission rates. Nevertheless, use of HFNC during the invasive ventilation and NIV weaning process could have some positive influence in reducing hospital LOS by shortening the time on the general ward after pediatric ICU discharge.

\section{REFERENCES}

1. Toledo del Castillo B, Fernández Lafever SN, López Sanguos C, Díaz-Chirón Sanchez L, Sánchez da Silva M, López-Herce Cid J. [Evolution of non-invasive ventilation in acute bronchiolitis]. An Pediatr (Barc) 2015;83(2):117-122.

2. Velasco Arnaiz E, Cambra Lasaosa FJ, Hernández Platero L, Millán García Del Real N, Pons-Òdena M. Is a nasopharyngeal tube effective as interface to provide bi-level noninvasive ventilation? Respir Care 2014;59(4):510-517.

3. Schibler A, Pham TM, Dunster KR, Foster K, Barlow A, Gibbons K, et al. Reduced intubation rates for infants after introduction of highflow nasal prong oxygen delivery. Intensive Care Med 2011;37(5): 847-852.

4. Riese J, Porter T, Fierce J, Riese A, Richardson T, Alverson BK. Clinical outcomes of bronchiolitis after implementation of a general ward high flow nasal cannula guideline. Hosp Pediatr 2017;7(4):197203.

5. Wing R, James C, Maranda LS, Armsby CC. Use of high-flow nasal cannula support in the emergency department reduces the need for intubation in pediatric acute respiratory insufficiency. Pediatr Emerg Care 2012;28(11):1117-1123.

6. Borckink I, Essouri S, Laurent M, Albers MJ, Burgerhof JG, Tissières $\mathrm{P}$, et al. Infants with severe respiratory syncytial virus needed less ventilator time with nasal continuous airways pressure then invasive mechanical ventilation. Acta Paediatr 2014;103(1): 81-85.

7. Mayordomo-Colunga J, Pons-Òdena M, Medina A, Rey C, Milesi C, Kallio M, et al. Non-invasive ventilation practices in children across Europe. Pediatr Pulmonol 2018;53(8):1107-1114

8. Flores-González JC, Mayordomo-Colunga J, Jordan I, Miras-Veiga A, Montero-Valladares C, Olmedilla-Jodar M, et al. Prospective multicentre study on the epidemiology and current therapeutic management of severe bronchiolitis in Spain. Biomed Res Int 2017;2017: 2565397.

9. Oñoro G, Pérez Suárez E, Iglesias Bouzas MI, Serrano A, Martínez De Azagra A, Garcia-Teresa MA, et al. [Severe bronchiolitis. Changes in epidemiology and respiratory support]. An Pediatr (Barc) 2011; 74(6):371-376.

10. Kepreotes E, Whitehead B, Attia J, Oldmeadow C, Collison A, Searles A, et al. High-flow warm humidified oxygen versus standard low-flow nasal cannula oxygen for moderate bronchiolitis (HFWHO RCT): an open, phase 4, randomised controlled trial. Lancet 2017; 389(10072):930-939. 


\section{Management of Respiratory FailuRe IN THE PICU}

11. Franklin D, Babl FE, Schlapbach LJ, Oakley E, Craig S, Neutze J, et al. A randomized trial of high-flow oxygen therapy in infants with bronchiolitis. N Engl J Med 2018;378(12):1121-1131.

12. Crane SD, Elliott MW, Gilligan P, Richards K, Gray AJ. Randomised controlled comparison of continuous positive airways pressure, bilevel non-invasive ventilation, and standard treatment in emergency department patients with acute cardiogenic pulmonary oedema. Emerg Med J 2004;21(2):155-161.

13. Yañez LJ, Yunge M, Emilfork M, Lapadula M, Alcántara A, Fernán$\operatorname{dez} \mathrm{C}$, et al. A prospective, randomized, controlled trial of noninvasive ventilation in pediatric acute respiratory failure. Pediatr Crit Care Med 2008;9(5):484-489.

14. Balaguer M, Alejandre C, Vila D, Esteban E, Carrasco JL, Cambra FJ, et al. Bronchiolitis Score of Sant Joan de Deu: BROSJOD score, validation and usefulness. Pediatr Pulmonol 2017;52(4):533-539.

15. McConnochie KM. Bronchiolitis. What's in the name? Am J Dis Child 1983;137(1):11-13.

16. Principi N, Esposito S.Biomarkers in pediatric community-acquired pneumonia. Int J Mol Sci 2017;18(2). pii: E447.

17. Dellinger RP, Levy MM, Carlet JM, Bion J, Parker MM, Jaeschke R, et al. Surviving Sepsis Campaign: international guidelines for management of severe sepsis and septic shock: 2008. Intensive Care Med 2008;34(1):17-60.

18. Essouri S, Durand P, Chevret L, Balu L, Devictor D, Fauroux B, et al. Optimal level of nasal continuous positive airway pressure in severe viral bronchiolitis. Intensive Care Med 2011;37(12):20022007.

19. Ganu SS, Gautam A, Wilkins B, Egan J. Increase in use of noninvasive ventilation for infants with severe bronchiolitis is associated with decline in intubation rates over a decade. Intensive Care Med 2012;38(7):1177-1183.
20. Pons-Odena M, Palanca D, Modesto V, Esteban E, González-Lamuño $\mathrm{D}$, Carreras R, et al. $\mathrm{S}_{\mathrm{pO}_{2}} / \mathrm{F}_{\mathrm{IO}_{2}}$ (S/F ratio) as a predictor of NIV failure in children with hypoxemic respiratory insufficiency. J Pediatr Intensive Care 2013;2:111-119. Available at https://www.thiemeconnect.com/ products/ejournals/issue/10.1055/s-005-29844. Accessed on August 30th, 2017.

21. Ricart S, Marcos MA, Sarda M, Anton A, Muñoz-Almagro C, Pumarola $\mathrm{T}$, et al. Clinical risk factors are more relevant than respiratory viruses in predicting bronchiolitis severity. Pediatr Pulmonol 2013;48(5):456-463.

22. Ricart S, Rovira N, Garcia-Garcia JJ, Pumarola T, Pons M, MuñozAlmagro C, et al. Frequency of apnea and respiratory viruses in infants with bronchiolitis. Pediatr Infect Dis J 2014;33(9):988-990.

23. Millán N, Alejandre C, Martinez-Planas A, Caritg J, Esteban E, Pons-Òdena M. Noninvasive respiratory support during pediatric ground transport: implementation of a safe and feasible procedure. Respir Care 2017;62(5):558-565.

24. Lemyze M, Mallat J, Nigeon O, Barrailler S, Pepy F, Gasan G, et al. Rescue therapy by switching to total face mask after failure of face mask-delivered noninvasive ventilation in do-not-intubate subjects in acute respiratory failure. Crit Care Med 2013;41(2):481-488.

25. Ferreira JC, Chipman DW, Hill NS, Kacmarek RM. Bilevel vs ICU ventilators providing noninvasive ventilation: effect of system leaks: a COPD lung model comparison. Chest 2009;136(2):448-456.

26. Itagaki T, Bennett DJ, Chenelle CT, Fisher DF, Kacmarek RM. Performance of leak compensation in all-age ICU ventilators during volume-targeted neonatal ventilation: a lung model study. Respir Care 2017;62(1):10-21.

27. Riese J, Fierce J, Riese A, Alverson BK. Effect of a Hospital-wide High-Flow Nasal Cannula Protocol on Clinical Outcomes and Resource Utilization of Bronchiolitis Subjects Admitted to the PICU. Hosp Pediatr 2015;5(12):613-618. 